\title{
Knowledge and Attitude of Togolese Radiographers on Medical Irradiation of Pregnant Women
}

\author{
Adambounou $\mathrm{K}^{1,2^{*}}$, Achy $\mathrm{OB}^{3}$, Fiagan $\mathrm{YA}^{2}$, Adigo $A M Y^{1}$, Mondé $\mathrm{K}^{1}$, Gbande $\mathrm{P}^{2}$, Sonhaye $\mathrm{L}^{1}$, Tapsoba $\mathrm{TL}^{4}$ and $A d j e n o u ~ K V^{1}$ \\ ${ }^{1}$ Service de Radiologie, CHU Campus de Lomé 05BP 633 Lomé 05, Togo \\ ${ }^{2}$ Laboratoire de Biophysique et Imagerie Médicale-Université de Lomé, Togo \\ ${ }^{3}$ Laboratoire de Biophysique -Université de Cocody-Abidjan, Togo \\ ${ }^{4}$ Laboratoire de Biophysique-Université de Ouagadougou, Togo
}

*Corresponding author: Adambounou Kokou, Service de Radiologie, CHU Campus de Lomé 05BP 633 Lomé 05, Togo, Tel: 00228 90 19 16 33; E-mail: kadambounou@yahoo.fr

Received date: July 07, 2015, Accepted date: July 31, 2015, Publication date: Aug 05, 2015

Copyright: @ 2015 Adambounou K, et al. This is an open-access article distributed under the terms of the Creative Commons Attribution License; which permits unrestricted use; distribution; and reproduction in any medium; provided the original author and source are credited.

\begin{abstract}
Purpose: Evaluate the knowledge and the attitude of the Togolese radiographers on the medical irradiation of pregnant women.

Materials and Methods: Cross-sectional study performed in April, 2011 about 72 radiographers of the public and private hospitals in Togo.

Results: The quarter of the radiographers thought that the MRI is an irradiant examination and $44.5 \%$ of them did not know that the scintigraphy uses ionizing radiations. There were $77.7 \%$ to consider that the pregnancy is not an absolved contraindication for any irradiant medical imaging modality. They thought in $88.8 \%$ of the cases that radiography must be realized only in the first ten days of the menstrual cycle of women old enough to procreate. The majority of the radiographers $(72.3 \%)$ did not ask the date of last menstruation of the women before undergoing the examination. None recorded the exposure parameters used for the irradiation of the pelvis in young women. The great majority of the radiographers $(86.1 \%)$ did not wear lead aprons for the pregnant women during the examinations and $83.3 \%$ of them have already refused to realize an unjustified radiography to the pregnant women. Globally, the erroneous knowledge on the biological effects of ionizing radiations and on radiation protection rules of the pregnant woman, were more counted with radiographers having more than 10 years of work experience.
\end{abstract}

Conclusion: It is concluded that the Togolese should take special attention to standard for women exposed to ionizing radiation. In-service training in radiation protection of the patients should be encouraged in Togo.

Keywords: Medical irradiation; Pregnancy; Ionizing radiations; Radiographers; Radiation protection

\section{Introduction}

The medical use of ionizing radiation is the largest source of radiation worldwide $[1,2]$. The benefits of the use of ionizing radiation (IR) in medicine for over 100 years are undisputed; however its use should be wisely and sparingly done. The biological effects of ionizing radiation are without any real doubt and sometimes dangerous to humans. These biological harmful effects, whether they are deterministic or stochastic, are more pronounced in children and especially in pregnant women [3]. Therefore, exposure of a female pregnant patient or professional very often leads to a concern disproportionate to the risk and inappropriate behaviour [4]. The phobia of x-rays often leads health workers to deprive pregnant women of some medical imaging techniques even though they were justified. Others still ignore the risks of exposure of pregnant women to ionizing radiation prescribed as first-line medical imaging radiation to the pregnant women. The respect for the rules of protection of pregnant women against the IR allow necessarily continuous training in radiation protection, which is actually mandatory in the developed countries for all medical staff using the IR [5]. The Medical training and seminars on radiation protection are sorely lacking in developing countries like Togo. One rightly wonders about the conditions of exposure of pregnant women to IR in Togo. In practical section in diagnostic radiology and nuclear medicine, the responsibility of an unjustified exposure of pregnant females with IR lies with both prescriber and the operator of examination [4]. We therefore undertook this work which has the objective to assess the knowledge and attitude of radiographers on the irradiation of the pregnant women.

\section{Materials and Methods}

A cross-sectional study with a questionnaire realized in conformity with literature data in April 2011 was filled by 72 radiographers (technicians) in radiology departments in Public and Private Health facilities in Togo.

The questionnaire was divided into three parts:

- Demographics data of the radiographers (regulatory, professional experience). 
Citation: Adambounou K, Achy OB, Fiagan YA, Adigo AMY, Monde K, et al. (2015) Knowledge and Attitude of Togolese Radiographers on Medical Irradiation of Pregnant Women. J Nucl Med Radiat Ther S7: S7-003. doi:10.4172/2155-9619.1000S7-003

Page 2 of 5

-Knowledge about irradiating medical imaging and biological effects of ionizing radiation on pregnant women.

-The practical guide to radiation protection adopted during the exposure of a pregnant woman.

Elaboration of the questionnaire and data analysed were performed using the software Sphinx. Processing and data analysis were performed on Microsoft software Word and Excel 2010.

\section{Results}

\section{Demographics data of radiographers}

Thirty eight radiographers, which represent $52.8 \%$, practiced in University Hospital Center (UHC), 8 radiographers (11.1\%) were working in Regional Hospital Center (RHC) and the remaining 26 (36.1\%), were working in private clinics. Twenty five percent of the radiographers have experience less than 5 years, 33.3\% between 5 years to 10 years, and $41.7 \%$ more than 10 years.

\section{Level of knowledge of the radiographers on physical principles of medical imaging modalities and biological effects of ionizing radiation on pregnant women}

Table 1 shows that a quarter of Radiographers thought that MRI is irradiation processing ; $44.5 \%$ of them do not know that scintigraphy uses ionizing radiation, and some of them in University Hospital Center (UHC) thought that ultrasound is radiating modality. It also highlights that overall; radiographers working in private structures had a better understanding of medical imaging modalities using the IR. Over three-quarters of the radiographers believed that pregnancy is not an absolute contraindication for any irradiating medical imaging technique (Table 2). All the radiographers knew that the medical community is not the only source of exposure to ionizing radiation. As it can be seen from the Table 3, only about one-tenth of the radiographers thought that an X-ray examination; if it is justified can be performed only in the first 10 days of the menstrual cycle; the vast majority knew that there are less risk to request radiography to a pregnant woman in the third quarter of pregnancy; just over half felt that diagnostic radiology delivered rarely some doses susceptible to generate fetal malformations; majority ignores that radiography performed in a pregnant woman may be responsible for a sooner or later cancer in the unborn child. In general, misconceptions about medical ionizing radiation of pregnant women were collected from more radiographers over 10 years of professional experience (Table 3 ).

\begin{tabular}{|c|c|c|c|c|c|c|c|c|c|c|}
\hline & \multicolumn{2}{|c|}{ Rx conv* } & \multicolumn{2}{|c|}{$\begin{array}{l}\text { Echograp } \\
\text { hy }\end{array}$} & \multicolumn{2}{|l|}{ Ст } & \multicolumn{2}{|c|}{$\begin{array}{l}\text { Scintigrap } \\
\text { hy }\end{array}$} & \multicolumn{2}{|c|}{ MRI } \\
\hline & $\mathrm{n}$ & $\%$ & $n$ & $\%$ & $n$ & $\%$ & $\mathrm{n}$ & $\%$ & $\mathbf{n}$ & $\%$ \\
\hline $\mathrm{UHC}$ & 38 & 100 & 02 & 05.2 & 38 & 100 & 22 & 57.8 & 12 & 31.5 \\
\hline $\mathrm{RHC}$ & 08 & 100 & 00 & 00.0 & 08 & 100 & 04 & 50.0 & 02 & 25.0 \\
\hline $\begin{array}{l}\text { Private } \\
\text { clinics }\end{array}$ & 26 & 100 & 00 & 00.0 & 26 & 100 & 14 & 53.8 & 04 & 15.3 \\
\hline Total & 72 & 100 & 02 & 02.7 & 72 & 100 & 40 & 55.5 & 18 & 25.0 \\
\hline
\end{tabular}

${ }^{*}$ Rx conv: Conventional Radiology

Table 1: Distribution of medical imaging examinations using ionizing radiation according to health structures of radiographers.

\begin{tabular}{|c|c|c|c|c|c|c|c|c|c|c|c|c|}
\hline & \multicolumn{2}{|c|}{ Rx conv ${ }^{*}$} & \multicolumn{2}{|c|}{$\begin{array}{l}\text { Echogra } \\
\text { phy }\end{array}$} & \multicolumn{2}{|l|}{ Ст } & \multicolumn{2}{|c|}{$\begin{array}{l}\text { Scintigra } \\
\text { phy }\end{array}$} & \multicolumn{2}{|c|}{ MRI } & \multicolumn{2}{|c|}{ None } \\
\hline & $\mathrm{n}$ & $\%$ & $n$ & $\%$ & $\mathrm{n}$ & $\%$ & $\mathrm{n}$ & $\%$ & $n$ & $\%$ & $\mathrm{n}$ & $\%$ \\
\hline UHC & 02 & $\begin{array}{l}05 . \\
2\end{array}$ & 00 & 00.0 & 10 & $\begin{array}{l}26 . \\
3\end{array}$ & 04 & 10.5 & 02 & $\begin{array}{l}05 . \\
2\end{array}$ & 30 & $\begin{array}{l}78 . \\
9\end{array}$ \\
\hline $\mathrm{RHC}$ & 02 & $\begin{array}{l}25 . \\
0\end{array}$ & 00 & 00.0 & 04 & $\begin{array}{l}50 . \\
0\end{array}$ & 02 & 25.0 & 00 & $\begin{array}{l}00 . \\
0\end{array}$ & 04 & $\begin{array}{l}50 . \\
0\end{array}$ \\
\hline $\begin{array}{l}\text { Privates } \\
\text { clinics }\end{array}$ & 02 & $\begin{array}{l}07 . \\
6\end{array}$ & 00 & 00.0 & 04 & $\begin{array}{l}15 . \\
3\end{array}$ & 02 & 07.6 & 00 & $\begin{array}{l}00 . \\
0\end{array}$ & 22 & $\begin{array}{l}83 . \\
6\end{array}$ \\
\hline Total & 06 & $\begin{array}{l}08 . \\
3\end{array}$ & 00 & 00.0 & 18 & $\begin{array}{l}25 . \\
0\end{array}$ & 08 & 11.1 & 02 & $\begin{array}{l}02 . \\
7\end{array}$ & 56 & $\begin{array}{l}77 . \\
7\end{array}$ \\
\hline
\end{tabular}

Table 2: Distribution of medical imaging modalities absolutely contraindicated in a pregnant according to health structures of radiographers.

\begin{tabular}{|l|l|l|l|l|l|l|l|l|}
\hline & \multicolumn{2}{l}{ Q1 } & \multicolumn{2}{l}{ Q2 } & \multicolumn{2}{l|}{ Q3 } & \multicolumn{2}{l|}{ Q4 } \\
\hline & $\mathbf{n}$ & $\%$ & $\mathbf{n}$ & $\%$ & $\mathbf{n}$ & $\%$ & $\mathbf{n}$ & $\%$ \\
\hline -5years & 28 & 87.5 & 30 & 93.7 & 14 & 43.7 & 06 & 18.7 \\
\hline 5-10years & 24 & 100 & 20 & 83.3 & 16 & 66.6 & 18 & 75.0 \\
\hline +10years & 12 & 75.0 & 10 & 62.5 & 08 & 50.0 & 04 & 25.0 \\
\hline Total & 64 & 88.8 & 60 & 83.3 & 38 & 52.7 & 28 & 38.8 \\
\hline
\end{tabular}

Q1: An x-ray if justified, can be applied to a woman in genitally active period after the first 10 days of the menstrual cycle?

Q2: Do you think that there is less risk to perform an $\mathrm{x}$-ray to a pregnant woman in the third trimester of pregnancy?

Q3: Are you of the opinion that the radio diagnostic rarely delivered doses susceptible to cause fetal malformations issue?

Q4: An X-ray performed on a pregnant woman can be responsible for a cancer early or later in the unborn child?

Table 3: Distribution of correct answers to questions about radiobiology of pregnancy according to professional experience of radiographers.

\section{The practical attitudes of radiation protection adopted during the exposure of ionizing radiation of a pregnant Woman}

Sixty two radiographers (which represent $86.1 \%$ ), have already performed an X-ray examination to a pregnant woman. Only one quarter $(25 \%)$ had already performed radiography of the uterine contents.

The results reported in Table 4 shows that the majority of radiographers did not ask the date of last menstruation of the women genitally active before subjecting them a radiological examination; no radiographer recorded the exposure parameters on a card after irradiating the pelvis of a woman genitally active; only $13.9 \%$ of radiographers did not wear apron for pregnant women; most of them had refused to perform an X-ray examination to a pregnant woman because it was not justified; overall bad attitudes were increasingly adopted in the public services. 


\begin{tabular}{|l|l|l|l|l|l|l|l|l|}
\hline & \multicolumn{3}{l}{ Q1 $^{*}$} & \multicolumn{2}{l}{ Q2 } & \multicolumn{2}{l|}{ Q3 } & \multicolumn{2}{l|}{ Q4 } \\
\hline & $\mathbf{n}$ & $\%$ & $\mathbf{n}$ & $\%$ & $\mathbf{n}$ & $\%$ & $\mathbf{n}$ & $\%$ \\
\hline UHC & 08 & 21.0 & 00 & 00.0 & 30 & 78.95 & 32 & 84.2 \\
\hline RHC & 02 & 25.0 & 00 & 00.0 & 08 & 100 & 06 & 75.0 \\
\hline Privates clinics & 10 & 38.4 & 00 & 00.0 & 24 & 92.3 & 22 & 84.6 \\
\hline Total & 20 & 27.7 & 00 & 00.0 & 62 & 86.1 & 60 & 83.3 \\
\hline & & & &
\end{tabular}

Q1: Do you ask the date of last menstruation to women in genital activity before performing them a radiology examination?

Q2: Do you record the constants on a card in case you exposure the pelvis of a woman in genital activity with ionizing radiations?

Q3: Do you wear an apron to a pregnant woman before performing their radiographic examinations?

Q4: Have you ever refused to perform X-ray examinations to pregnant women because it is not justified?

Table 4: Distribution of correct answers to questions about good attitudes of radiation protection according to radiographer's health structures.

\section{Discussion}

Physical principles of various medical imaging modalities are not all based on the use of ionizing radiation, it is important that the operators in general and radiographer in particular, had to master very well all this techniques before performing the irradiating exam especially in the cases of pregnant women. Accordingly, it is comforting to know that all Togolese radiographers knew that conventional radiography and CT scan are irradiating techniques; it is a pity that $5.2 \%$ of handlers of the UHC in service for over 10 years assumed that ultrasound is a technique of ionizing radiation. Ultrasound, whose physical principle is based on the transmission and reception by an ultrasonic wave sensor with a piezoelectric elements, is non-invasive radiation, inexpensive and can be the most appropriate imaging modality for pregnant women $[6,7]$.

The ignorance of the physical principle of nuclear medicine by $44.5 \%$ of Togolese radiographers can be partly explained by the lack of health service in Nuclear medicine in the country. Our study also reveals that a quarter of Togolese radiographers thought that MRI is an ionizing irradiation procedure, the disappointing results of these is not surprising if we know that according to a study done in France by Gervais et al. in 2011, almost 10\% of French prescribers also believed that MRI uses ionizing radiation [8].

Pregnancy, as affirmed by quarter of Togolese radiographer is not an absolute contraindication for CT scans which are very irradiant. Is it necessary to recall that the pelvis scan is a CT scan commonly achieved by first intention in the evaluation of biometrics pelvic bone of suspected cephalopelvic disproportion or in case of breech presentation [9]. Indeed, as it is also known by majority of Togolese radiographers, pregnancy is not an absolute contraindication to any examination of radiating medical imaging. It is only a relative contraindication [10].

Since the clinical examination is justified, ie the benefits of its realization before delivery are higher than the risks during the pregnancy and no technical alternative medical imaging based on non ionizing radiation is available, a diagnostic examination using IR can be performed to a pregnant woman [11].
Besides the principle of justification mentioned above satisfied, the radiographer must also obey strictly to the second principle of radiation protection which is "optimization". With the respect of this second principle, a large part of the responsibility of radiographer should be to maintain exposure as low as possible, i.e. to conform to the ALARA principle.

A minority of radiographers (11.1\%) continue to believe that radiography, if it is justified cannot be achieved to women genitally active unless they are in the first 10 days of the menstrual cycle. The rule which advise, to avoid an irradiant examination after the first ten days following menstruation is now useless because its lack of validity has been demonstrated [12,13]. Indeed, before implantation (day 10 after fertilization); this is a mechanism for all or none [10,11].

The theoretical risk of deterministic effects or tissue reactions (malformation) on the embryo and maximum fetus during embryogenesis (10th day at the beginning of the 10th week), is the minimum third quarter, and it is encouraging to note that the majority of Togolese radiographers (83.3\%) knew it.

The study performed by Cordoliani et al. $[4,14]$ explains the low risk of deterministic effects occurred in late pregnancy. It is due to the fact that during the fetal maturation in the third quarter, the organs are formed and the death of a group of cells cannot lead to a minor or partial malformation of an organ. An important exception is the brain knowing the crucial stage of development and also neuronal mutation.

At this stage, the exposure to ionizing radiation can lead to mental retardation. The occurrence of malformation effects imply exposure of pregnant women at a dose above the threshold of 100-200 mGy; dose threshold as stated in $52.7 \%$ of radiographers in our study is generally not exceeded during an exam of diagnostic radiology [2,15]. Therefore, the risk of malformation is almost zero for pregnant women in diagnostic radiology, if the radiation protection measurements are respected. While all the radiographers should know and assure the safety of patients with a phobia for X-ray.

In contrast, the radiographers should always keep in mind the risk of stochastic effects inherent to any exposure of ionizing radiation, even at low doses in which the risk in the embryo or fetus can be higher. These risks of stochastic effects, as it has been pointed out by the $61.2 \%$ of radiographers, reveal the form of cancer at early or later stage in children who will be born.

It is therefore understandable that exposure of pregnant women to ionizing radiation should be avoided to the possible amount either pregnancy is known or not. Finding out the pregnancy in female patients is the initial responsibility of both the doctor who has requested for examination and the radiographers who should always inquire for this possibility.

It is therefore worrying that the majority of Togolese radiographers (72.22\%) did not enquire the date of last menstruation from a woman genitally active before performing radiography. This bad attitude of Togolese radiographers is also observed in $82.7 \%$ of radiographers in Ivory Coast according to the study done by Kwame et al in 2009 in the radiology department at UHC Yopougon in Abidjan [16].

The study reported by James et al. in 2011 shows that this neglect in the initial search for pregnancy in female patients is unfortunately observed in Nuclear Medicine services In Australia according [17].

If the exposure of a pregnant woman is decided or if it is concerning particularly the pelvis of a woman in childbearing age, the 
radiographer has to document dosimetric parameters (Dose input; Dose Area Product) and record absolute constant (KV, mAs, ect.) used during the exam.

These constants should also be reported in the income proceedings of the radiologist to allow subsequent estimation of the dose especially during an irradiation of an unrecognized pregnancy [18,19]. It is therefore regrettable that the radiographers never recorded the constants of their exams even those performed in pregnant women. In addition to this obligation to indicate all elements needed to estimate doses, the radiographers should faithfully take into account all precautions to dose optimization so that the dose delivered to the uterus should be as low as possible.

For this purpose, it is recalled that wearing a lead apron during the exam performed in far from the pelvic (for instance: cliche of knee or shoulder, Panoramic dental, scanner head) does not change significantly the dose to the pelvis but it might be useful for the psychological comfort of the patient.

Wearing apron for patients by the majority of radiographers of our study is therefore to be welcomed. Our study reveals that, the most erroneous knowledge on irradiation medical pregnancy were collected from the radiographers with more than 10 years experience and this is due to the lack of training in radiation protection in radiology in Togo.

Interestingly, the study performed by Ongolo Zongo et al. in 2013 [20], shows a similar situation in Cameron, according to which more than half professional DATR (Directly Assigned to work with ionizing radiation) have an average level of knowledge of the principles and standards of radiation protection, also more than $80 \%$ have never participated in radiation protection training.

In addition, bad attitudes adopted during irradiation of the pregnant woman are more remarkable in the public services of Togolese radiology practice in which unfortunately the majority of radiographers and radiological services are more important. Eventually, it is urgent that continuous trainings on radiation protection are regularly organized for radiographers.

Additionally, radiology services should be performed by the skillful persons in radioprotection in order to better protection not only for patients but also for caregivers against the deleterious effects of ionizing radiation. This continuous radiation safety training which led to some radiographers refusing to perform unjustified radiation exposure to pregnant women, should also be extended to prescribers to that level so that they can stop prescribing an inappropriate examination with high frequency radiation exposure to a pregnant woman. A recent study performed by Akintomide and Ikpeme in Nigeria [21] which has shown that the level of compliance of the physicians with the referral guidelines for women of reproductive age is poor, confirm the necessity to extend this radiation safety training to the prescribers.

\section{Conclusion}

The level of knowledge's of Togolese radiographers in irradiation of pregnant female is relatively acceptable and varies according to their health structures and professional experiences. Good attitudes are not always adopted upon exposure of pregnant women to ionizing radiations. This might be related to the lack of regular training in radiation protection in Togo. Correspondingly, efforts still need to be done both by health authorities as well as radiographers to ensure judicious and rational exposure of pregnant patients to ionizing radiation in health centers in Togo.

\section{References}

1. Scanff P, Donadieu J, Pirard P, Aubert B (2008) Population exposure to ionizing radiation from medical examinations in France. Br J Radiol 81: 204-213.

2. de Broucker T, Pontana F, Santangelo T, Faivre JB, Tacelli N, et al. (2012) Single- and dual-source chest CT protocols: Levels of radiation dose in routine clinical practice. Diagn Interv Imaging 93: 852-858.

3. McCollough CH, Schueler BA, Atwell TD, Braun NN, Regner DM, et al. (2007) Radiation exposure and pregnancy: when should we be concerned? Radiographics 27: 909-917.

4. Cordoliani YS, Foehrenbach H (2003) Grossesse et exposition médicale. Feuillets de radiologie 43:154- 159.

5. Société Française de Radiologie (2009) Guide pratique à l'usage des médecins radiologues pour l'évaluation de leurs pratiques professionnelles. Paris.

6. http://www.em-consulte.com/es/article/57200/bases-physiques-ettechnologiques-de-l-echographie.

7. Adambounou K, Farin F, Boucher A, Adjenou KV, Gbeassor M, et al. (2012) Plate forme de télé imagerie gynéco-obstétricale " bas prix ». Imagerie de la Femme 22: 49-56.

8. Gervaise A, Esperabe-Vignau F, Pernin M, Naulet P, Portron $\mathrm{Y}$, et al. (2011) [Evaluation of the knowledge of physicians prescribing CT examinations on the radiation protection of patients]. J Radiol 92: 681-687.

9. Garnier S, Bertrand P, Chapiron C, Asquier E, Rouleau P, et al. (2004) [Low dose helical CT pelvimetry: evaluation of radiation dose and image processing]. J Radiol 85: 747-753.

10. Doublali M, Chouaib A, El fassi MJ, et al. (2010) Examens d'imagerie chez la femme enceinte: les urgences urologiques chez la femme enceinte. Espã $\odot$ rance m $\tilde{\odot} \odot$ dicale A 17: 137-139.

11. Wang PI, Chong ST, Kielar AZ, Kelly AM, Knoepp UD, et al. (2012) Imaging of pregnant and lactating patients: part 2, evidence-based review and recommendations. AJR Am J Roentgenol 198: 785-792.

12. Karen M, Puneet B, Kalpana MK, Sandeep V, Brent KS, et al. (2010) Imaging in Pregnant Patients: Examination Appropriateness. RadioGraphics 30: 1215-1233.

13. Cordoliani YS (2002) [Pregnancy and medical radiation: to demystify and take the drama out of managing]. J Radiol 83: 595-597.

14. Cordoliani YS, Foehrenbach H (2008) Radioprotection en milieu $\mathrm{m} \tilde{A} \odot$ dical-Principes et mise en pratique. Paris: Masson.

15. Khadzhidekova V, Shishkova R, Khadzhidekov V (2001) [Effects of ionizing radiation on the embryo and fetus]. Akush Ginekol (Sofiia) 41: 24-28.

16. Kouame N, Ngoan-Domoua AM, SétchéouA, Nezou BJP, Konan KD, et al. (2012) Grossesse et risques d'irradiations en radiodiagnostic : état des connaissances des usagers au CHU de Yopougon (Abidjan, Côte d'Ivoire). Radioprotection 47: 553-560.

17. James DJ, Cardew P, Warren-Forward HM (2011) Determining the pregnancy status of patients before diagnostic nuclear medecine procedure: the Australian experience. J Nucl Med Technol 39: 220-25.

18. Weisser G, Steil V, Neff KW, Büsing KA (2012) [Radiology and pregnancy. Principles, general requirements and exposure]. Radiologe 52: 81-90.

19. Brisse H, Sirinelli D, Chateil J, Cordoliani Y, Aubert B, et al. (2007) [Including exposure dose in radiological reports: how? why?]. J Radiol 88: 411-414.

20. Ongolo-Zogo P, Nguehouo MB, Yomi J, Nkoâ $€^{\mathrm{m}}{ }^{\mathrm{w}} \mathrm{e}$ Amven S (2013) Connaissances en matière de radioprotection: enquête auprès des personnels des services hôspitaliers de radiodiagnostic,radiothérapie et médecine nucléaire à Yaoundé Cameroun. Radioprotection 48: 39-49. 
Citation: Adambounou K, Achy OB, Fiagan YA, Adigo AMY, Monde K, et al. (2015) Knowledge and Attitude of Togolese Radiographers on Medical Irradiation of Pregnant Women. J Nucl Med Radiat Ther S7: S7-003. doi:10.4172/2155-9619.1000S7-003

21. Akintomide AO, Ikpeme AA (2014) Radiation safety of women of the reproductive age: evaluation of the role of referring physicians. J Family Med Prim Care 3: 243-246. 